\title{
LA VENTANA COLECTORA
}

\section{(THE COLLECTOR WINDOW)}

Santiago Vega Amado, Dr. Arquitecto

Profesor Titular de la Universidad de Valladolid. España.

\section{RESUMEN}

El presente artículo aboga por el rediseño de los huecos de iluminación para que sirvan también como eficaces huecos térmicos. Las estrategias de captación y rechazo solar de los sistemas solares pasivos conocidos le llevan a definir un original "hueco bioclimático" que denomina "ventana colectora".

\section{SUMMARY}

Present article defend the idea for improving light-opening designs in the objetive of thermic efficiency as such hollows. Solar gaining and rejecting strategies in passive systems drive to author to define a original "bioclimatic hollow" named by him as "collector window".

OBJETIVO.-El prefijo "vent" de la palabra ventana denota que en sus orígenes la ventilación fue su principal cometido; sin embargo, la iluminación lograda a su través, condicionará las tipologías fundamentales hasta nuestros días. Estas breves notas tratarán de explicar cómo los esfuerzos recientes por procurar calor a través de ellas apuntan hacia el comienzo de nuevas tipologias.

\section{CAPTACIÓN Y PROTECCIÓN SOLAR}

Los huecos sombreados y carentes de vidrios son los propios de los climas tropicales, ya que deben asumir permanentemente la doble función de ventilar e iluminar. La ventilación constante mejora la transpiración, y la iluminación tamizada logra la deseada penumbra interior.

Los climas fríos necesitan interponer los vidrios en los huecos para limitar la ventilación y mantener la deseada iluminación. En ocasiones, incluso, la ventilación se aleja definitivamente del hueco, produciéndose ésta por conductos específicos lejanos a él.

La implantación del vidrio en el hueco consigue no sólo eliminar o dosificar la ventilación, sino también evitar el arrastre térmico que ésta conlleva. Hasta mucho tiempo después de sus primeros usos, no fuimos capaces de sentir que era, además, una trampa para el calor generado por la propia luz natural que le habia traspasado. La intuición popular detectará, muchos siglos después, que este efecto consecủentemente aumentaría en grandes superficies acristaladas, por lo que se extendió su uso en todas las regiones norteeuropeas, donde la gran inclinación de los rayos solares en invierno lo justificaba, y donde los avances técnicos lo permitirian. Estábamos en los precedentes de los actuales sistemas bioclimáticos que tienden a la captación energética para climas fríos.

La misma intuición popular que luchó por esta captación supo dar soluciones arquitectónicas de "protección" para climas cálidos. Si la ventilación arrastra calor, la luz lleva calor. La Arquitectura mediterránea se significará por la incesante búsqueda de la sombra. Las persianas y partesoles evitarán siempre el paso directo de la radiación solar por el vidrio, alejándose con ello el riesgo de sobrecalentamiento interior. Sólo se tolerará el paso de la luz "de sombra", es decir, aquella que la persiana pudo descargar de su contenido energético fundamental. 


\section{EL MOVIMIENTO INTERNACIONAL COMO RECHAZO BIOCLIMÁTICO}

El movimiento internacional terminará con esta diferenciada respuesta arquitectónica entre el Norte y el Sur. Los nuevos materiales descubiertos permitieron liberar a la fachada de su misión portante en beneficio de esbeltos soportes puntuales, terminándose con la estructura muraria que siempre habia limitado el tamaño del vano. El Sur, que siempre había buscado soluciones arquitectónicas de "protección", rasga y amplifica los huecos de sus fachadas - muros ventanas o muros cortina-, con lo que sus nuevas propuestas pasan a ser las propias de los climas fríos o de "Captación", con el consiguiente sobrecalentamiento interior que ello conlleva. Se habría un nuevo camino que unificaría todas las arquitecturas por la vía de la indigestión tecnológica.

Mientras "Roma" lograba la unificación constructiva por la vía de la fuerza y el Renacimiento basaba su difusión por la vía de la persuasión cultural, el movimiento internacional surge de sociedades cultural $y$ económicamente en ebullición que basan su fácil propagación en el deslumbramiento tecnológico en sociedades en crisis. Sólo así se podrá entender la fuerza carismática y seductora de tales movimientos que obvian condicionantes climáticos o culturales propios.

\section{RESPUESTAS DE PROTECCIÓN SOLAR}

Será Le Corbusier el primero en controlar el paso excesivo de luz al interior de los edificios vidriados del movimiento moderno. La acuñación en castellano del término francés "brise soleil" pudo con su sinónimo "partesol". Se empieza a entender la necesidad de proporcionar sombras a las grandes superficies acristaladas que Mies proponía, y comienza un período obsesivo por situar una fachada "rompedora del rayo solar".

La tecnología actual permite que el propio vidrio reduzca el paso de luz y energía solar. Del vidrio transparente se ha pasado al vidrio reflectante o "atérmico". Se puede llegar ya a prescindir de los partesoles.

Las superficies acristaladas buscan ellas mismas protegerse buscando disminuir la transmisión solar al interior. Para ello se utilizan, unas veces, vidrios de fuerte absorción y gran poder de reemisión posterior al exterior; y otras veces se prefiere recurrir al uso de láminas reflectantes superpuestas al vidrio (Fig. 1).

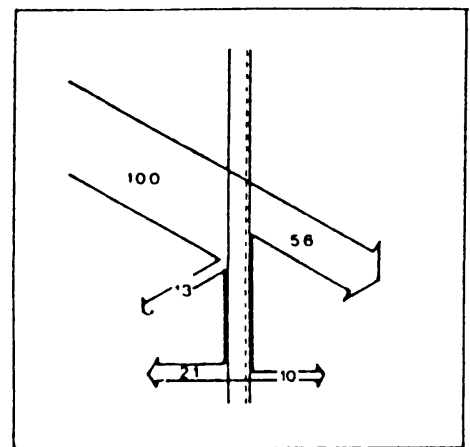

Vidrio reflectante $6 \mathrm{~mm}$

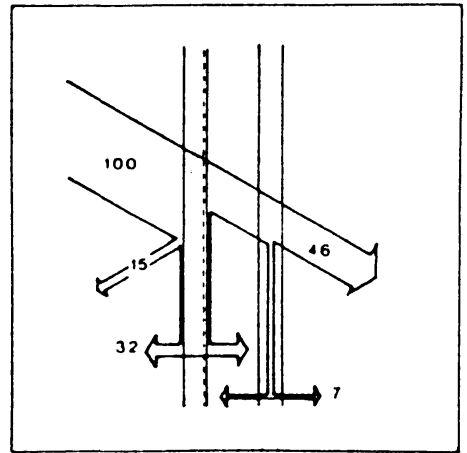

Vidrio reflectante $6 \mathrm{~mm}$. Vidrio transparente $6 \mathrm{~mm}$.

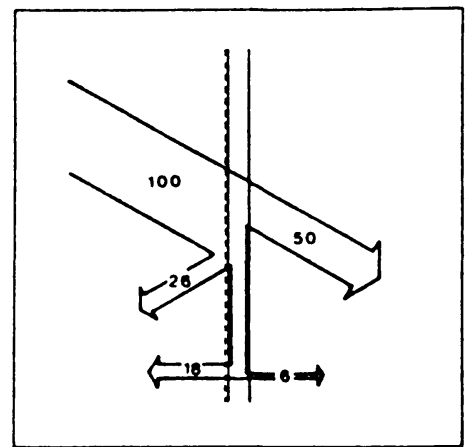

Vidrio reflectante $6 \mathrm{~mm}$.

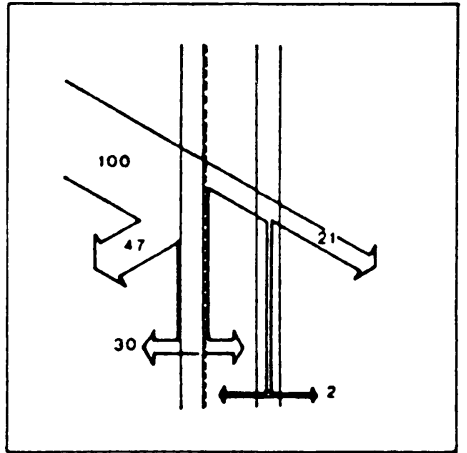

Vidrio reflectante $6 \mathrm{~mm}$. Vidrio transparente $6 \mathrm{~mm}$

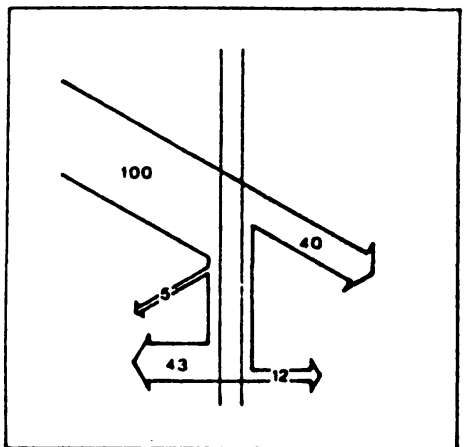

Vidrio absorbente $6^{3} \mathrm{~mm}$.

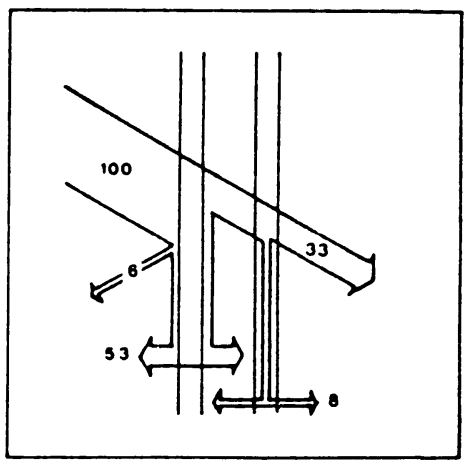

Vidrio absorbente $6 \mathrm{~mm}$.

Vidrio transparente $6 \mathrm{~mm}$.

SOLUCIONES ANTITÉRMICAS'.-Los vidrios reflectantes requieren de una delgada capa de óxido metálico. Esta capa debería estar colocada exteriormente, pero es dificil de mantener. Cuando se coloca en el interior del vidrio interior de un doble acristalamiento puede producir un sobrecalentamiento excesivo en la propia cámara con posible riesgo de rotura. La mejor ubicación seria en la cara interior del vidrio exterior. 


\section{RESPUESTAS DE CAPTACIÓN}

Pero el vidrio no siempre debe ser protegido de la radiación solar, a veces nos sirve para calentar el interior en climas o estaciones frías. El cristal de un hueco acristalado sirve de fácil paso a las longitudes de onda corta de la radiación solar y absorben las de larga longitud de onda en las que aquellas son transformadas por los materiales del interior. El Ilamado efecto invernadero de los huecos acristalados nos va a permitir que debamos considerar no solamente las características del cristal separadas, sino los tipos de material interior -inercia, color, difusividad térmica, etc. - y ya no podremos hablar más de hueco acristalado sin más. Debemos hablar de hueco climático, y más exactamente lo que denomino "hueco bioclimático". Se intuye que podremos sacar mejor rendimiento al calor captado en función de las características y diseño del hueco bioclimático (Fig. 2).

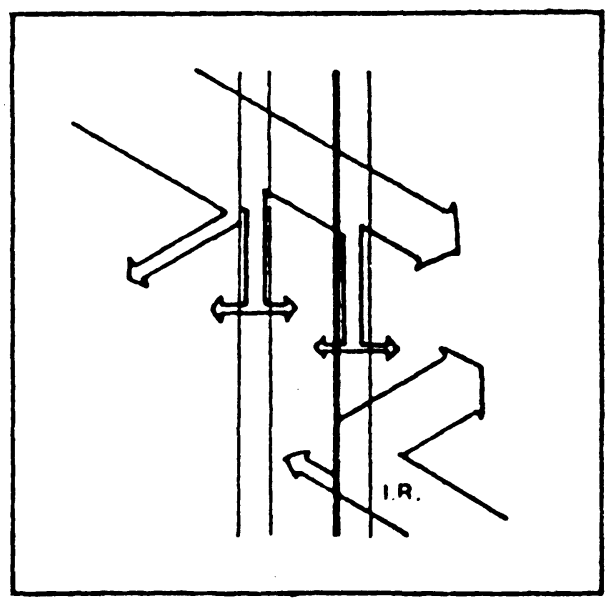

Fig. 2

COMPORTAMIENTO DEL DOBLE VIDRIO COMO SUPERFI. CIE CAPTORA. - La pérdida de calor a través del vidrio doble colector puede ser reducido si se coloca una fina capa de óxido metálico por la cara que da a la cámara de aire del vidrio interior. Su baja emisividad y su poder reflexivo devuelve al interior las ondas infrarrojas de larga longitud de onda mientras que permite el fácil paso de los rayos solares al in. terior del edificio. La pérdida de calor a través de este conjunto de doble vidrio equivale al $30 \%$ de lo que correspondería a un vidrio ordinario y sería equivalente al comporta. miento del conjunto de tres vidrios.

\section{EVOLUCIÓN DEL HUECO BIOCLIMÁTICO}

A continuación paso a exponer cronológicamente los pasos más significativos del hueco bioclimático acristalado. Terminaré exponiendo con mayor detalle lo que denomino "compacto de ventana colectora", que no es más que un colector de aire de superficie absorbente móvil (persiana).

\subsection{Del invernadero al "Muro Trombe"}

Intuitivamente el invernadero adosado, como hueco avanzado, parece abanderar las primeras respuestas. Sus etimologias sajonas - Sunspace y Green Houseparecen enfatizar la importancia del espacio habitable y su poder de captación térmica. Parece pues obligado que los norteamericanos prodiguen sus cualidades en esos primeros años de andadura bioclimática. Sólo cuando se consigue superar la idea del obligado "apéndice" al edificio, se lograrán los primeros éxitos de diseño.

La paulatina aproximación del vidrio del invernadero hacia el muro protegido y la transformación de éste, permitirá su evolución hacia la aparición del "Muro Trombe". Se favorecerá la absorción y acumulación térmica, debido al oscurecimiento exterior y al aumento de densidad del propio muro. Pequeñas perforaciones lograrán la necesaria convección del aire que favorecerá la distribución del calor almacenado.

\section{3}

\subsection{Del Muro Trombe al colector de aire}

Una nueva evolución permitirá que el "Muro Trombe" sustituya su muro acumulador por otro sin capacidad térmica alguna pero con gran poder aislante. Este nuevo sistema bioclimático denominado "Colector de aire" busca calentar directamente el aire para su inmediata distribución al interior. Para ello el aire es calentado hasta la temperatura impuesta al termostato, momento en que es impulsada al interior de la vivienda. Múltiples variedades de colectores de aire impregnan todas las soluciones bioclimáticas de los últimos cinco años. En los ejemplos reflejados he querido grafiar algunas de estas variantes.

Estos dos nuevos "huecos aparentes", el Muro Trombe y el Colector de aire, no logran ventilar ni iluminar, pero han logrado absorber y retener mejor el calor que los huecos acristalados convencionales (Figs. 3 a 8). 


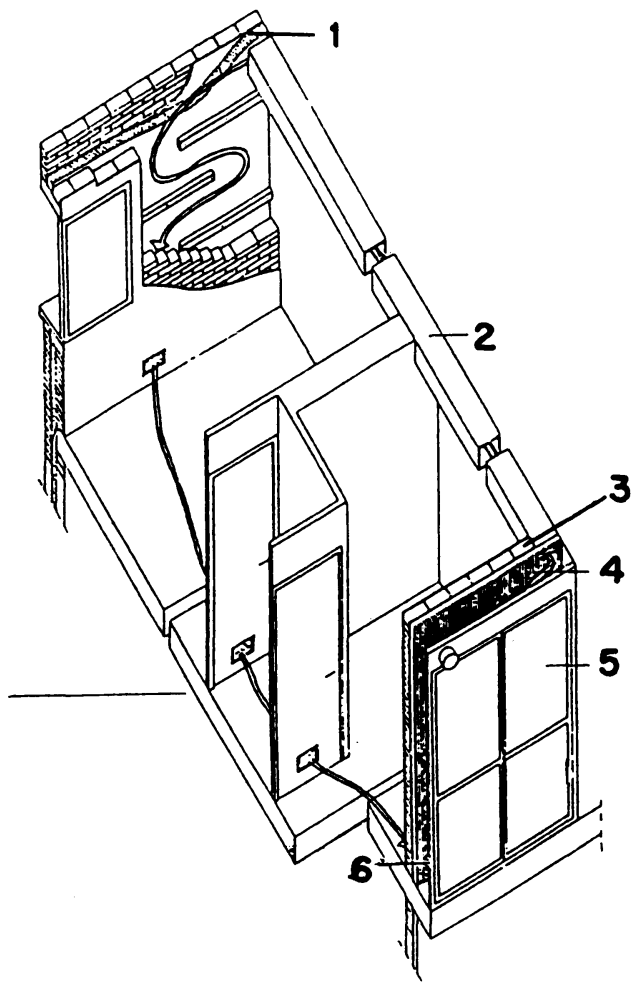

Del muro absorbente y pesado del Muro TROMBE, se pasa a un liviano aislante oscuro para seguir permitiendo la absorción pero impedir la acumulación del calor. Éste es directamente impulsado al interior.

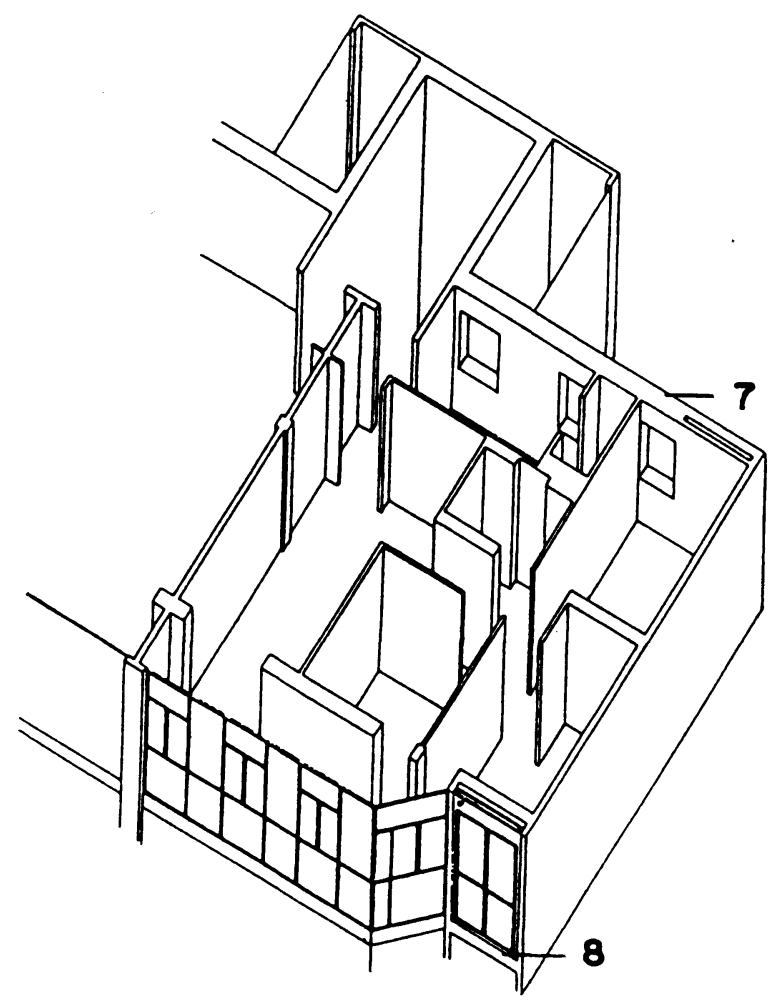

Axonometría de la vivienda abastecida térmicamente con el colector de aire.

1.-Muro acumulador. 2.-Conducto aire. 3.-Tabicón. 4.-Aislante absorbente (Polisocianurato). 5.-Vidrio 6 mm. 6.-Ventilador. 7.-Muro acumulado. 8.-Colector de Aire.

COLECTOR DE AIRE EN PEDRAJAS DE SAN ESTEBAN². - En este caso el aire es impulsado por ventilador hasta el muro acumulador alejado.
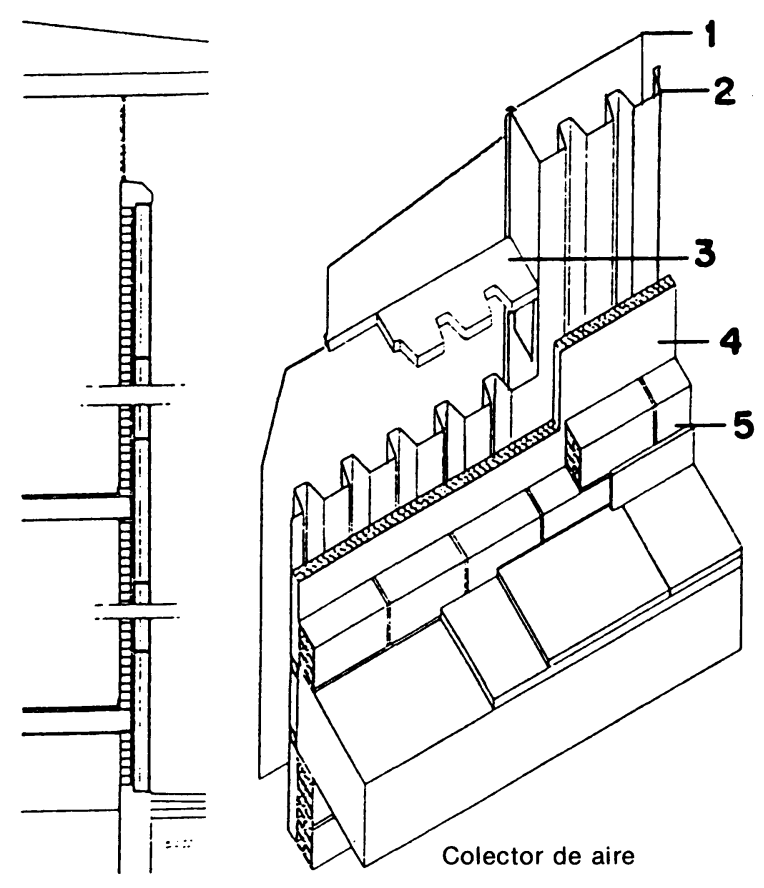

${ }^{2}$ Viviendas monitorizadas por el Departamento de Construcciones Arquitectónicas de la E.T.S.A. de Valladolid con la supervisión del CIEMAT.

(C) Consejo Superior de Investigaciones Científicas Licencia Creative Commons 3.0 España (by-nc)
Fig. 4

1.-Vidrio. 2.-Chapa nervada absorbente. 3.-Separador intermedio. 4.-Aislante. 5.-Trasdosado cerámico.

$$
3
$$

COGECES DEL MONTE. CENTRO ESCOLAR ${ }^{3}$ - Posee un único colector de aire central para todo el centro escolar. Su orientación capta los primeros rayos inclinados solares. Su frente ocluido y protección le protege de los vientos dominantes y del sol del verano.

Sus separadores en greca de poliestireno extruido reduce la estratificación térmica acusada y por ello reduce las pérdidas hacia el exterior del aire caliente mientras éste espera para ser enviado al interior.

\footnotetext{
${ }^{3}$ Proyectado por el autor de este artículo.
}

http://informesdelaconstruccion.revistas.csic.es 


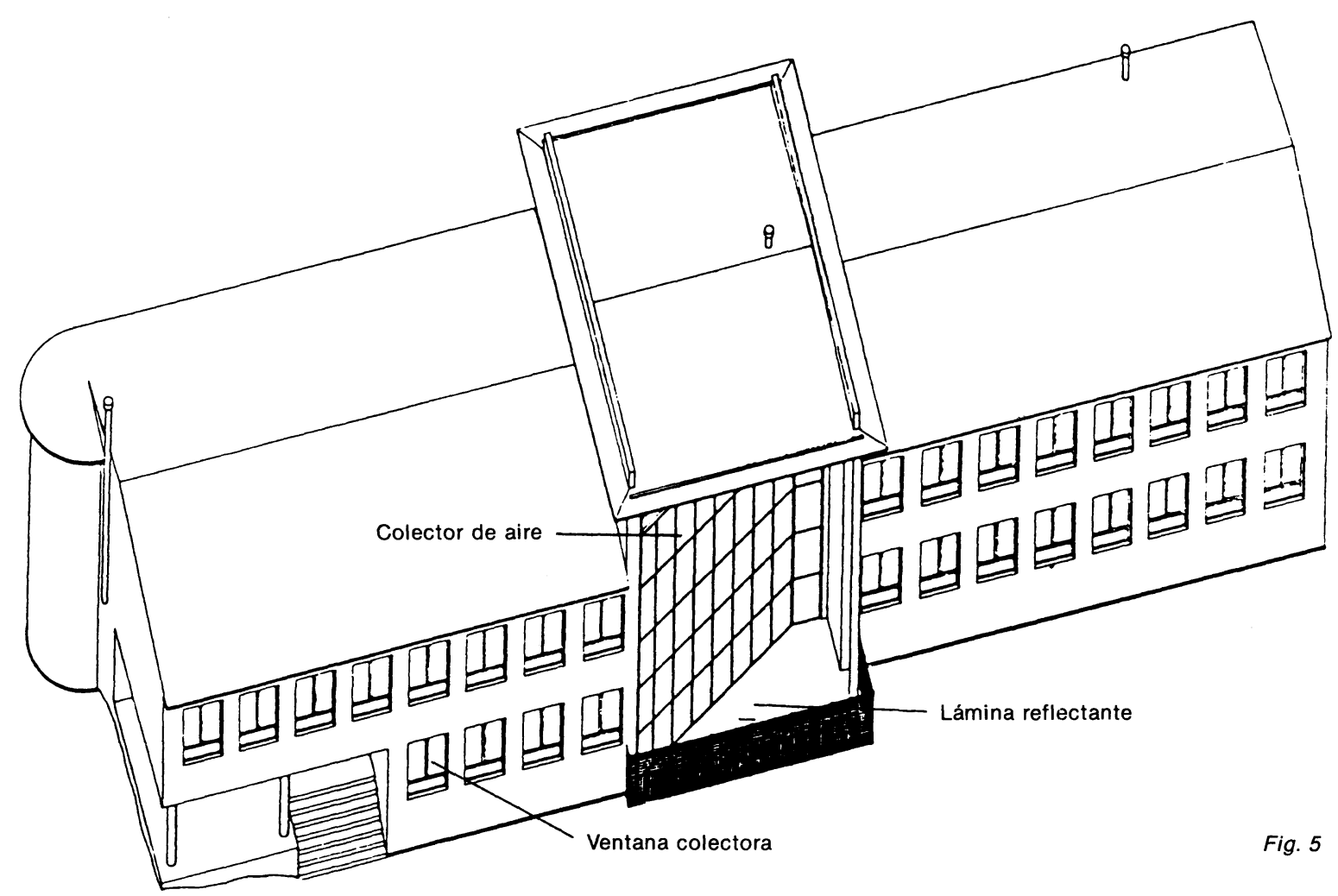

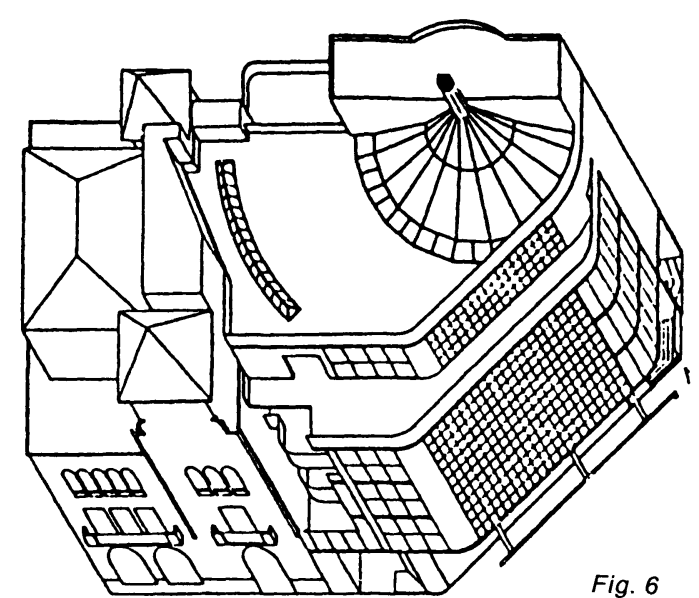

Fig. 6

CENTRO COMERCIAL. AXONOMÉTRICA DEL CONJUN. $\mathrm{TO}^{4}$.-Adosado a un edificio histórico. Las estrategias bioclimáticas son:

- Tubos mezcladores del aire estratificado situados en huecos interiores, funcionan por efecto chimenea.

- Calentamiento por colector de aire a S.E. y Trombe a S.

- Enfriamiento con chimenea solar semicircular situada en cubierta.

COLECTOR DE AIRE A S.E. Y MURO TROMBE AL S. - EI primero busca una respuesta inmediata a los primeros rayos del sol, de ahí su exposición directa a los primeros rayos de la mañana.

Fig. 7

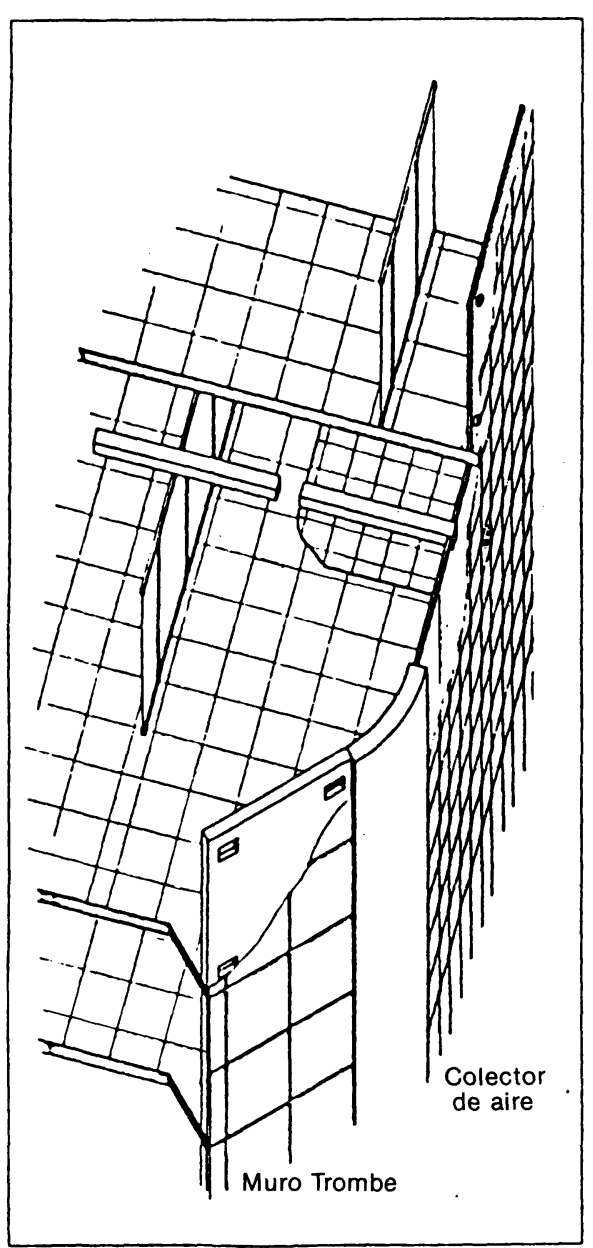

${ }^{4}$ Proyectado por el autor de este artículo. 


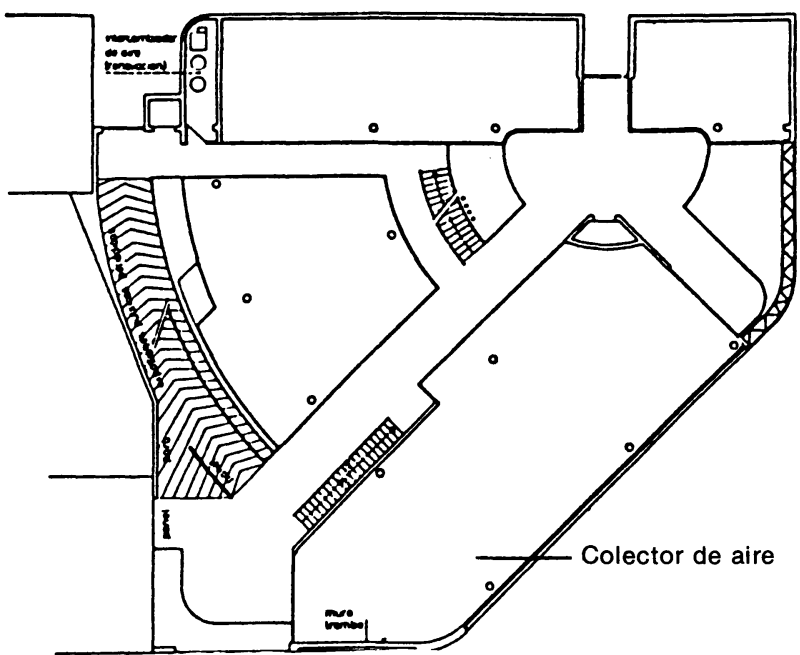

Planta 2.

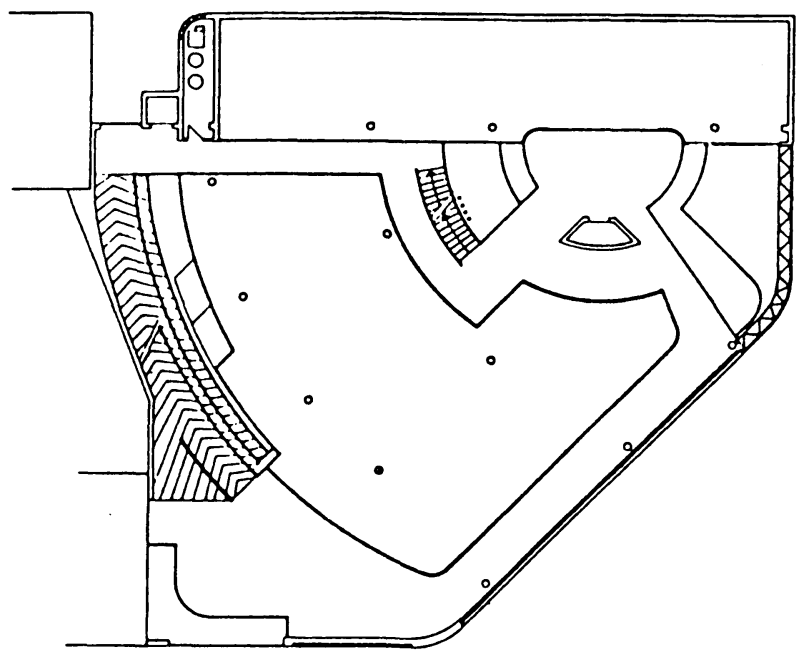

Planta 3.

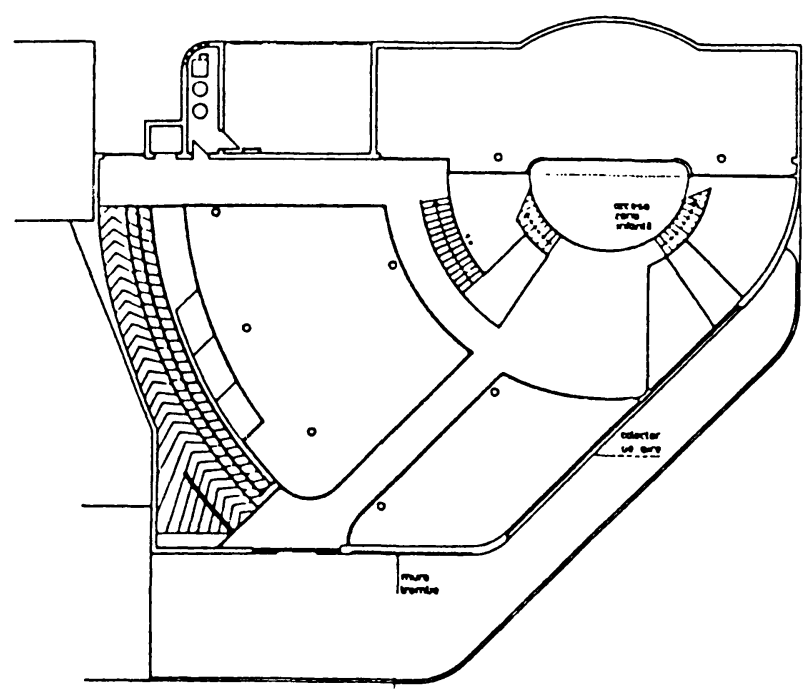

Planta 4.

\subsection{Ventana Colectora}

Propongo una tercera etapa en este errante camino bioclimático, el "compacto de ventana". Consta de dos ventanas que cierran una cámara cuyo aire servirá para calentar el interior del espacio a caldear. A través de esta cámara discurre la persiana de cierre. El aire calentado en su interior, lejos de permanecer confinado, y por tanto no utilizable térmicamente, se le hace circular al interior de la habitación a través de la propia tapa perforada de la cajonera de persiana. El propio acabado oscuro de las lamas de persiana acentuará su absorción térmica, sin riesgo alguno de deformación de ellas, ya que al existir una convección permanente el calor absorbido es enviado al interior por el obligado movimiento del aire (Fig. 9).
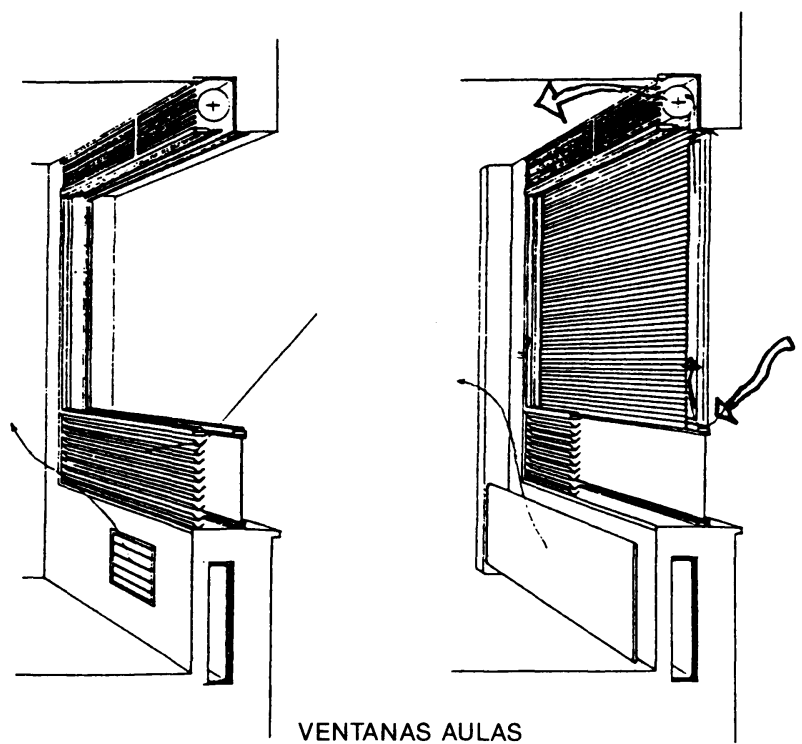

VENTANAS AULAS

Fig. 9

VENTANA. CENTRO ESCOLAR EN COGECES DEL MON $T^{5}$. - En este ejemplo, al haberse optado por una ventana corredera de débil estanquidad, el sistema actuará succionando el aire exterior y precalentándolo antes de introducir. lo como aire de renovación interior. 


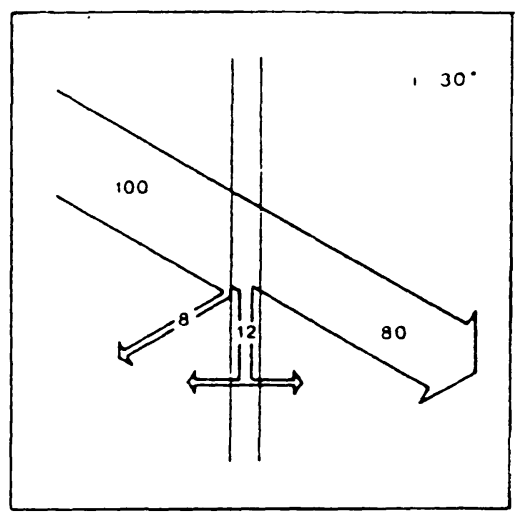

Vidrio sencillo transparente $6 \mathrm{~mm}$.

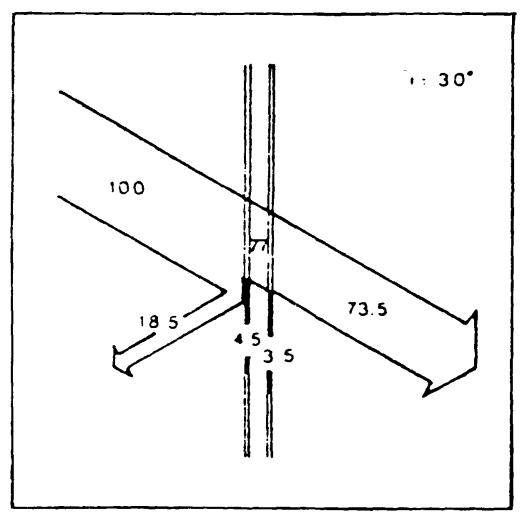

Policarbonato $6 \mathrm{~mm}$.

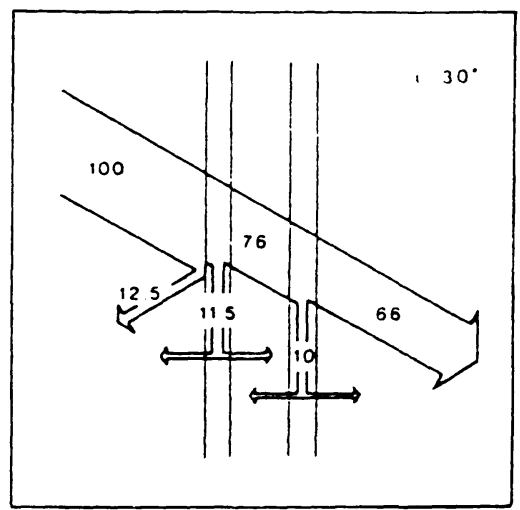

Doble vidrio transparente $6 \mathrm{~mm}-12 \mathrm{~mm}$.

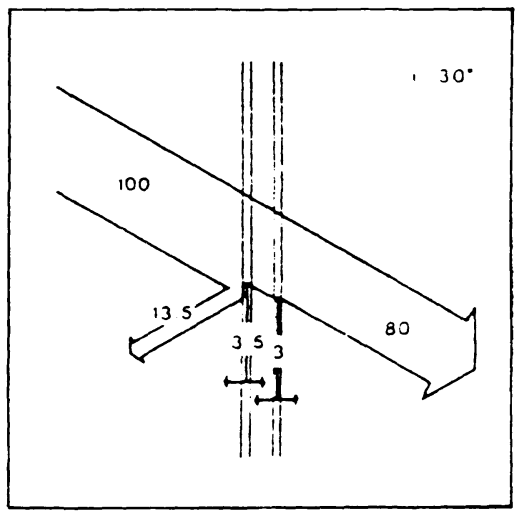

Metacrilato $8 \mathrm{~mm}$.

Fig. 10

Esta propuesta es particularmente aconsejable en edificios de gran aforo, debido a que en estos lugares es muy importante la renovación constante del aire. En estos casos la ventana colectora sirve para precalentar el aire de ventilación exterior antes de que penetre al interior. El aire de convección, que constantemente discurre por la cámara, succionará al de renovación a través de las guías de las ventanas correderas, incorporándose éste al ciclo convectivo interior.

Este nuevo hueco bioclimático se diferencia de los dos anteriores comentados en que recuperan las funciones de iluminación y visión que aquéllas perdieron. El cierre total o parcial de la persiana convierte a ésta en un móvil colector solar de aire, donde las lamas oscuras acentuarán la absorción, y donde el vidrio exterior producirá el deseado efecto invernadero. El calor confinado es introducido al interior por convección natural a través de la cajonera de la persiana. El descenso de las lamas de persiana se limitará con el fin de permitir permanentemente la entrada inferior del aire desde la habitación hasta la cámara de la ventana, que una vez calentado volverá a entrar superiormente por la cajonera. La regularización del tope inferior en el recorrido de la persiana podria hacer variar el tamaño de entrada y con ello el caudal convectivo y, consecuentemen te, la temperatura del aire calentado. Esta temperatura y las constantes conductivas del vidrio exterior serán factores decisivos en el rendimiento térmico del conjunto (Fig. 10).

\subsubsection{Orígenes de la Ventana Colectora}

Quizás convenga indicar que los avances tecnológicos en Arquitectura pasan siempre por "reconducir" fenómenos ya conocidos. La recapacitación eh los 70 de las propiedades ya conocidas del vidrio, permitió la sistematización de los sistemas bioclimáticos en Arquitectura.

La obsesiva duplicación de ventanas en muchos hogares españoles, como consecuencia de la crisis energética de los últimos años, con la finalidad de reducir las pérdidas térmicas del interior, delataba indirectamente los fundamentos de todo sistema bioclimático: el efecto invernadero. Si se logró disminuir las pérdidas de calor por los huecos, resultó que también se consiguió incrementar las ganancias solares diurnas, y fundamentalmente cuando se bajaba la persiana que se había visto involuntariamente encerrada en el espacio comprendido entre las dos ventanas. Como consecuencia, ésta se ennegrecía y se deformaba por las elevadísimas temperaturas alcanzadas. Era evidente que se vislumbraba un nuevo "hueco bioclimático" que exigiria un retoque a la cajonera de la persiana. Ésta 
debería permitir el paso del aire calentado, bien al interior -invierno-o al exterior - verano-.

\subsubsection{Denominación}

Si un sistema tan genuinamente español, como son las persianas de lamas, habia machaconamente conservado el término estructural "Capialzado" para algo que ya no era más que una "cajonera" que servía para albergar el bombo de la persiana, resultará que también ahora tendremos que seguir llamando "cajonera" a algo que reclama una nueva ubicación terminológica que he querido denominar "Ventana Colectora".

\section{USO DE VERANO DE LOS HUECOS BIOCLIMÁTICOS}

No quisiera terminar estas breves notas sin hacer alusión al papel que el usuario debe asumir en la utilización correcta de los huecos bioclimáticos. Decididamente si no se es capaz de sentir el clima, y por tanto, modificar adecuadamente las condiciones de captación o protección del hueco bioclimático, seguro que este usuario será pronto un declarado detractor de la Arquitectura Bioclimática.

Es un error pretender seguir calentando un espacio ya sobrecalentado y ello puede llegar a ocurrir en verano, por lo que se exige modificar los hábitos de utilización de huecos bioclimáticos durante períodos de calor.

El colector de aire, y en particular la "ventana colectora", permite teóricamente una "posición de verano" haciendo que el circuito de aire circulante por la cámara sea tomado desde el exterior, para que una vez calentado sea nuevamente expulsado al exterior. La presión de salida es aprovechada para succionar el aire fresco que discurre por el interior de la habitación. Cuando el colector de aire funciona como tal pasa a denominarse "Chimenea Solar". (Fig. 11).

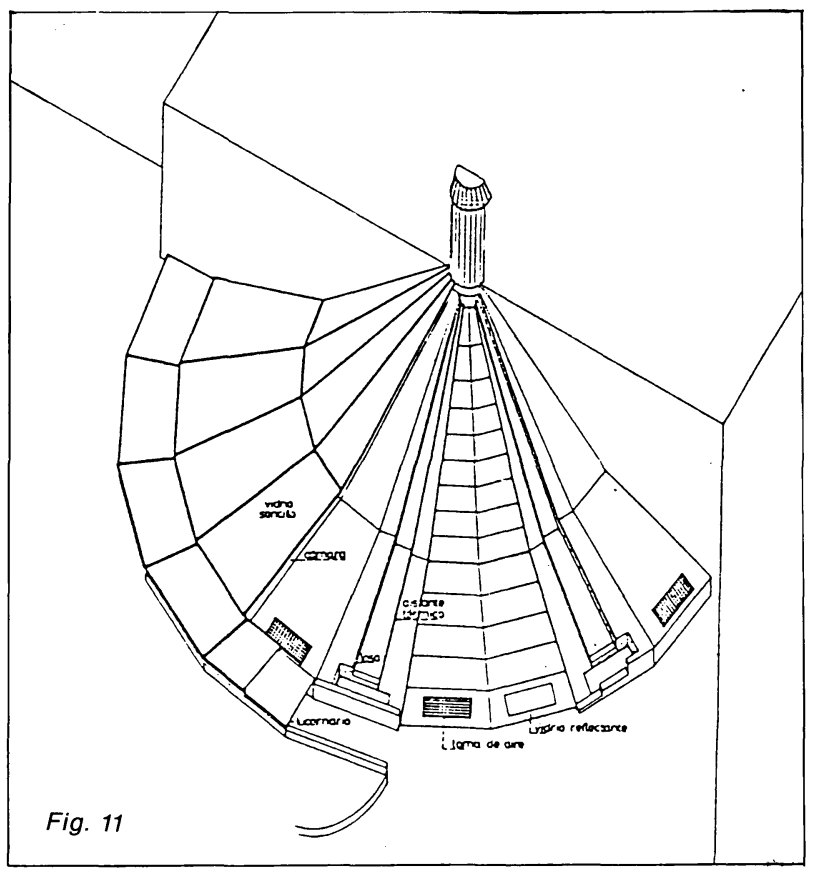

CHIMENEA SOLAR ${ }^{6}$ - Es un colector de aire dispuesto en posición de enfriar.

Sirve para acentuar la ventilación por el interior del local, debido a la succión provocada en las tomas de aire. La superficie plegada captora está sectorizada interiormente para permitir el funcionamiento independiente de los distintos tra. mos, de tal manera que a cualquier hora del día hay algún sector de chimenea solar en funcionamiento.

Para aumentar la succión se acentúa la altura única de la sa. lida superior del aire caliente, para provocar el efecto chime. nea. Incluso la absorción estática que ocasiona el remate tipo "Shunt" de éste, incrementará aún más esta circunstancia. Para terminar, se ha previsto en la toma interior de aire una torre evaporativa, con el fin de enfriar el aire de captación.

${ }^{6}$ Propuesta del autor.

\section{RECOMENDACIONES}

En la meseta castellana con sus noches frías de verano, es más ventajoso inutilizar o proteger los huecos bioclimáticos antes que hacerlos funcionar en posición inversa. Cori un correcto uso de los huecos convencionales durante el día y la noche, se podrán lograr ambientes interiores más frescos.

En general, no se aconseja nunca el uso alternativo de verano e invierno para un mismo hueco bioclimático.
En lugares de mucho aforo o en climas muy cálidos y húmedos, donde la ventilación es importante, se aconseja el uso de chimenea solar.

Para climas muy cálidos y secos es recomendable la chimenea solar, aunque en estos casos se aconseja el enfriamiento previo de la masa de aire circulante, haciéndola pasar por una lluvia pulverizada -enfriamiento evaporativo-. 